\title{
Evaluation of Outcome of Ureteroscopic Pneumatic Lithotripsy in Single Lower Ureteric Calculus and Its Association with CT Parameters
}

\author{
Rahul Bhatia, Tariq Hameed*, Pawan Lal, Lovenish Bains, Gaurish Sawant, Haraesh Maranna \\ Department of Surgery, Maulana Azad Medical College, New Delhi, India \\ Email: *drtariqhameed@gmail.com
}

How to cite this paper: Bhatia, R., Hameed, T., Lal, P., Bains, L., Sawant, G. and Maranna, H. (2019) Evaluation of Outcome of Ureteroscopic Pneumatic Lithotripsy in Single Lower Ureteric Calculus and Its Association with CT Parameters. Open Journal of Urology, 9, 153-161.

https://doi.org/10.4236/oju.2019.910018

Received: September 22, 2019

Accepted: October 14, 2019

Published: October 17, 2019

Copyright $\odot 2019$ by author(s) and Scientific Research Publishing Inc. This work is licensed under the Creative Commons Attribution International License (CC BY 4.0).

http://creativecommons.org/licenses/by/4.0/

\begin{abstract}
Objective: To evaluate the outcome of ureteroscopic pneumatic lithotripsy in single lower ureteric calculus and correlate its success with different CT parameters like HU, size of calculus and hydrnephrosis, if present. Patients and Methods: This study was conducted from October 2017 to March 2019 in Department of General Surgery, Maulana Azad Medical College, New Delhi. 30 patients (out of which 6 were excluded due to spontaneous passage of calculus), with single lower ureteric calculus were chosen and the outcome of URSL was compared with respect to CT parameters of Size, HU and Hydronephrosis and intra-operative clearance of calculus. Results: Success rate of URSL in single lower ureteric calculus was found to be $75 \%$. Lower HU $(774.12 \pm 212.85)$ was associated with higher success rate. Similarly smaller size of calculus $(9 \pm 2.1) \mathrm{mm}$ was associated with success group. Patients with gross hydronephrosis had a poor outcome of URSL. Lower urinary tract infection (8.33\%) was the most common complication. Conclusion: Patients with small size calculus, low $\mathrm{HU}$ and absence of hydronephrosis have a better outcome of URSL.
\end{abstract}

\section{Keywords}

Computed Tomography (CT), Ureteroscopic Lithotripsy (URSL), Hounsfield Unit (HU), Hydronephrosis (HDN)

\section{Introduction}

Ureteral stones are common (5\% - 12\%) urologic condition [1]. They are commonly made up of Calcium salts, while others are also made of other compounds like triple phosphates, cysteine and uric acid [2]. Due to this variability in its 
composition, the stones themselves can occur in various shapes, sizes and hardness. The stone may lie at different anatomical positions within the ureter, hence they are also classified as upper, middle and lower ureteric stone. Lower ureteric calculus (distal ureter + UVJ) is most common, more than $60 \%$ of all ureteric calculus [3].

Non Contrast Computed Tomography (NCCT) is accepted as one of the best imaging modality for detection and evaluation of ureteric calculus with sensitivity as high as $96 \%$ [4]. It is the imaging modality of choice during acute renal colic. Other than the anatomical details, we can rule out other pathologies that may mimic renal colic [5]. CT also helps in knowing about the nature or the hardness of the stone measured in terms of Hounsfield unit (HU) [6] [7]. In terms of position it tells the exact distance of the stone from PUJ/VUJ.

Ureteroscopic lithotripsy (URSL) is a good intervention modality for treatment of ureteric stones [8]. Its outcome is affected by size, position and nature of stones. In our study we are evaluating the outcome of URSL in lower ureteric calculus and its association with CT parameters. The parameters used are dimensions and $\mathrm{HU}$ of stone which depict the nature and size of stone.

\section{Material and Methods}

The study was conducted in department of General Surgery, Maulana Azad Medical College and Lok Nayak hospital, New Delhi from October 2017 to March 2019. It was a prospective study. A total of 30 patients were taken for study, which was done for a period of 1.5 years. Inclusion criteria was all adults ( $>18$ years) with diagnosis of single lower ureteric calculus on X-Ray KUB (Figure 1). Exclusion criteria were presence of ureteral injury/stricture, urinary tract infection, single kidney, renal failure. Out of the 30 patients, 6 were excluded due to spontaneous passage of stone. Remaining 24 patients underwent unenhanced helical computed tomography scan (Figure 2 \& Figure 3 ). The images were reviewed at a Picture Archiving and Communication System (PACS) workstation.

The size of the stone was measured using the dimension tool of Radiant DICOM software. The longest transverse diameter of stone was taken as the size of stone. Other stone factor used was height of stone in form number of axial cuts images of stone (slice thickness $5 \mathrm{~mm}$ ). The Hounsfield units (HU) for each stone were calculated for the cross-section with the largest diameter and the secondary sign like hydronephrosis was graded between $0-3$. All the CT studies were reviewed by radiologist who was blindfolded to pre and postoperative CT parameters.

Hydronephrosis was graded as follows: $0=$ absent, $1=$ prominence of the intrarenal pelvis or mild ureteral dilatation, $2=$ dilatation of the renal calices or moderate ureteral dilatation, and $3=$ severe dilatation of the collecting system [9].

Using a $10 \mathrm{~F}$ rigid ureteroscope, a guide wire was introduced in lower ureter and ureteroscope was advanced in lower ureter. Using pneumatic lithotripter the stone was broken and extracted using dormia basket or forceps. 


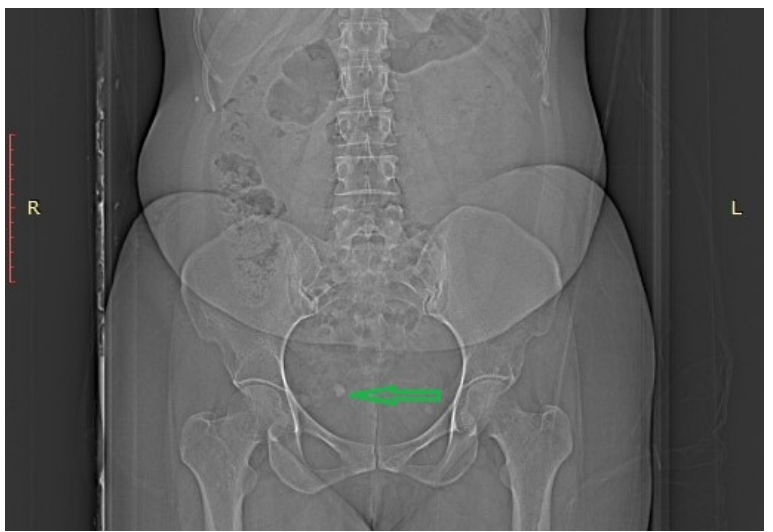

Figure 1. X-Ray KUB showing right lower ureteric calculus.

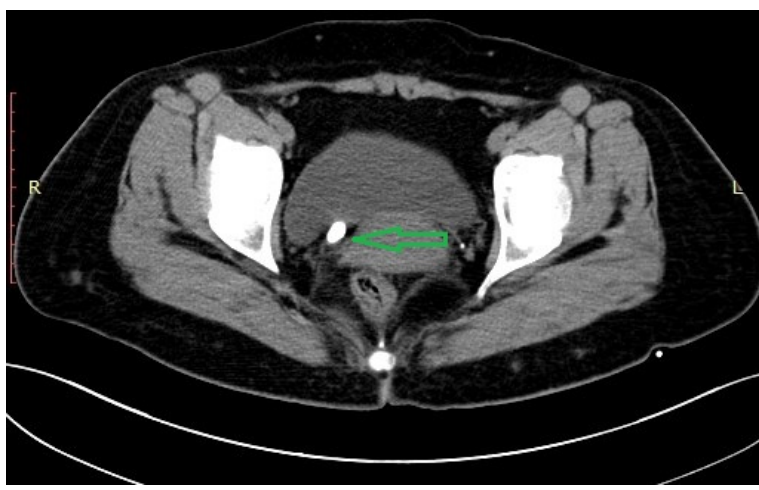

Figure 2. CT KUB showing right lower ureteric calculus.

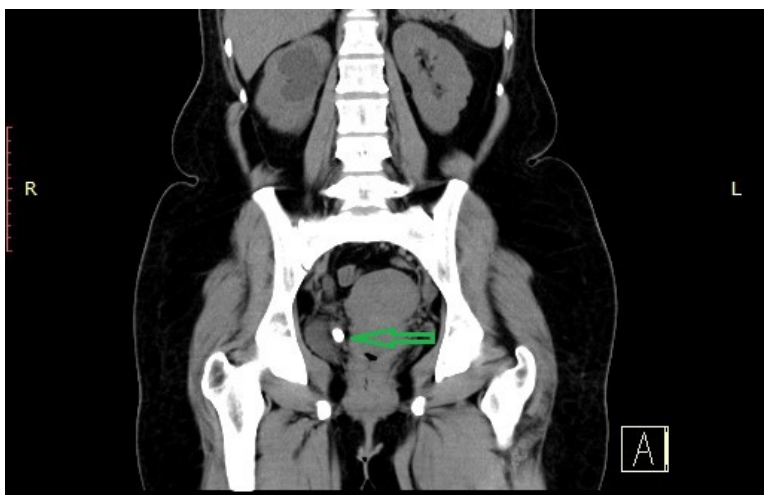

Figure 3. CT KUB with calculus in right lower ureter.

Statistical analysis was performed to evaluate the association between the outcome of URSL and patient's age and gender. We also evaluated the association between the outcome of URSL and CT parameters of the stone like size of the stone, Hounsfield unit. We also included hydronephrosis as secondary sign, duration and complication of the procedure as statistical parameters in our study.

All values are expressed as the mean \pm standard deviation. Categorical variables were presented in number and percentage (\%) and continuous variables were presented as mean \pm SD and median. Normality of data was tested by 
Kolmogorov-Smirnov test. If the normality was rejected then non parametric test was used. Analysis was done using Statistical Package for Social Sciences (SPSS) version 21.0. A $p$ value of less than 0.05 was considered significant.

\section{Results}

Data from 24 patients with single lower ureteric stone were analyzed. Outcome was classified as successful or failure, based on intra-operative clearance of stone and post operative CT findings. In our study 18 patients had complete removal of stones and 6 patients had failed outcome of URSL. The overall rate of treatment success was $75 \%(n=18)$ and the failure rate was $25 \%(n=6)$. The outcome of URSL was correlated with duration of the procedure and CT parameters such as size of stone (diameter and height), Hounsfield unit and presence of hydronephrosis. In group 1 (success group) the mean duration of URSL was 25.56 \pm 6.49 minutes and mean Hounsfield unit of stone was 774.12 $\pm 212.85 \mathrm{HU}$. In group 2 (failure group) the mean duration of URSL was $40.75 \pm 4.95$ minutes and mean Hounsfield unit of stone was 1193.12 $\pm 327.51 \mathrm{HU}$ (Table 1).

Out of 24 patients, 18 had positive outcome of URSL with mean size of stone 9 $\pm 2.1 \mathrm{~mm}$ and 6 had negative outcome with mean size of stone $12.5 \pm 3.3 \mathrm{~mm}$. The $\mathrm{p}$ value for stone size in relation to outcome was $<0.0004$ which was statistically significant (Figure 4).

In our study population the shortest duration of URSL was $15 \mathrm{~min}$ and the longest duration was $48 \mathrm{~min}$. Out of 24 patients, 18 had positive outcome of URSL with mean duration of procedure $25.56 \pm 6.49$ and 6 had negative outcome with mean duration of $40.75 \pm 4.95$. The $\mathrm{p}$ value for procedure duration was $<0.0001$ which was statistically significant (Figure 5 ).

Out of total sample size of the study $58.33 \%$ of patients had moderate hydronephrosis (HDN), 29.17\% had gross HDN and $12.50 \%$ had mild HDN. Patients with gross HDN had a poor outcome of URSL (Figure 6 \& Figure 7).

The patient's sex, age, height, weight, BMI and previous stone history did not differ significantly between group 1 and group 2 (Table 2 ).

The most common complication seen was lower urinary tract infection, which accounted for $8.33 \%$. Second most common complication was hematuria which accounted for $4.16 \%$. There was no evidence of any other known complication including ureteric perforation (Table 3 ).

\section{Discussion}

The success rate of URSL depends on the location of stone in the ureter, size of the stone, the use of surgical instruments including the ureteroscope, and the operator's surgical technique.

The stone size factors that were included in the study were longest diameter, transverse diameter, and height by CT axial cuts. Most studies have focused on the longest stone diameter for measuring stone size. However, Abdelrahim et al. [10] considered the transverse stone diameter, as this dimension generates the most resistance to the downward force applied by a basket or forceps. 
Table 1. Comparison of outcome of URSL in respect to duration of procedure, size and $\mathrm{HU}$ of calculus and Hydronephrosis.

\begin{tabular}{cccc}
\hline & $\begin{array}{c}\text { Success (Group 1) } \\
\text { Sample size 18 }\end{array}$ & $\begin{array}{c}\text { Failure (Group 2) } \\
\text { Sample size 6 }\end{array}$ & P value \\
\hline $\begin{array}{c}\text { Duration (minutes) } \\
\text { Mean } \pm \text { SD }\end{array}$ & $25.56 \pm 6.49$ & $40.75 \pm 4.95$ & $<0.0001$ \\
HU & & & 0.001 \\
Mean \pm SD & $774.12 \pm 212.85$ & $1193.12 \pm 327.51$ & \\
Size (mm) & & & 0.004 \\
Mean \pm SD & $9 \pm 2.1$ & $12.5 \pm 3.3$ & \\
$\begin{array}{c}\text { Hydronephrosis } \\
\text { (grade 0/1/2/3) }\end{array}$ & $0 / 3 / 13 / 2$ & $0 / 0 / 1 / 5$ & 0.001 \\
\hline
\end{tabular}

Table 2. Comparison of various parameters in success and failure group.

\begin{tabular}{cccc}
\hline Parameters & Success (group 1) & Failure (group 2) & p value \\
\hline Sex (m/f) & $14 / 4$ & $5 / 1$ & $>0.05$ \\
Age (years) & $26.75 \pm 6.2$ & $26.80 \pm 6.1$ & $>0.05$ \\
Height (cm) & $160.66 \pm 9.3$ & $160.56 \pm 9.6$ & $>0.05$ \\
Weight (kg) & $65.3 \pm 8.7$ & $66.1 \pm 8.3$ & $>0.05$ \\
BMI (kg/m $\left.{ }^{2}\right)$ & $25.2 \pm 3.4$ & $24.6 \pm 3.2$ & $>0.05$ \\
Previous stone history & & $2 / 4$ & $>0.05$ \\
(present/not) & $6 / 13$ & & \\
\hline
\end{tabular}

Table 3. Complications after URSL.

\begin{tabular}{ccc}
\hline Complications & Number & Percentage \\
\hline Ureteric perforation & 0 & Zero \\
Hematuria & 1 & 4.16 \\
Lower urinary tract infection & 2 & 8.33 \\
\hline
\end{tabular}

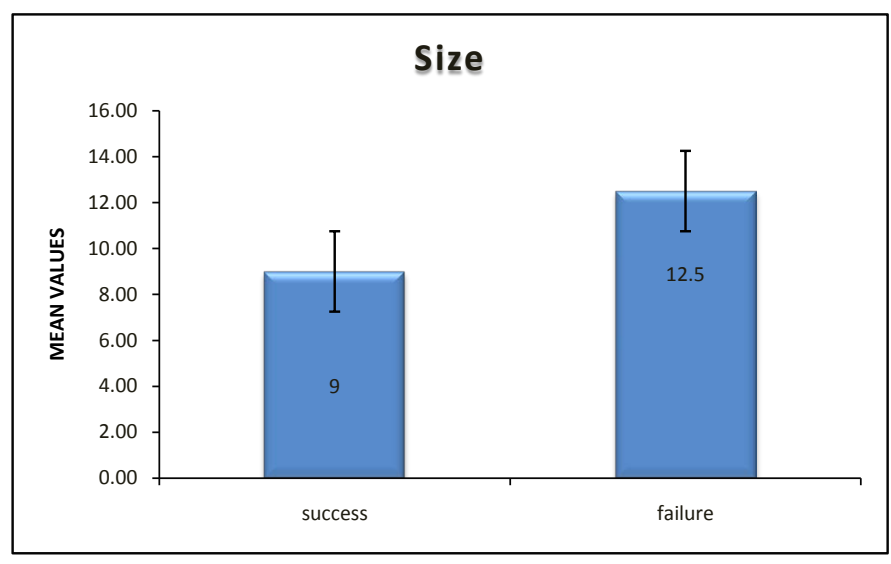

Figure 4. size of stone with outcome of URSL. 


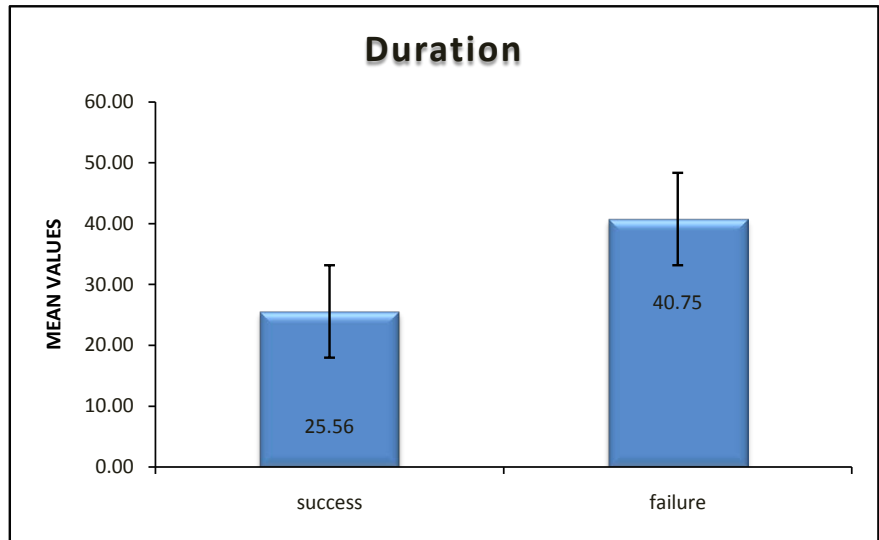

Figure 5. Duration with outcome of URSL.

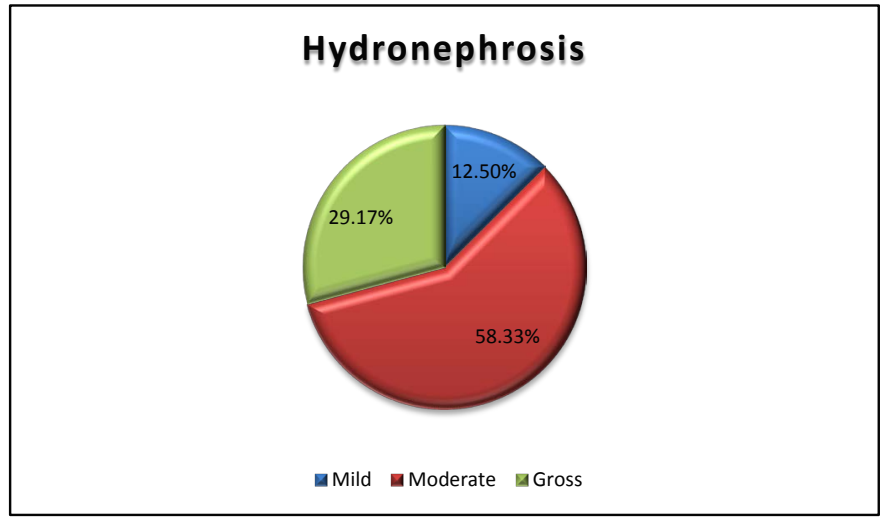

Figure 6. Distribution of Hydronephrosis.

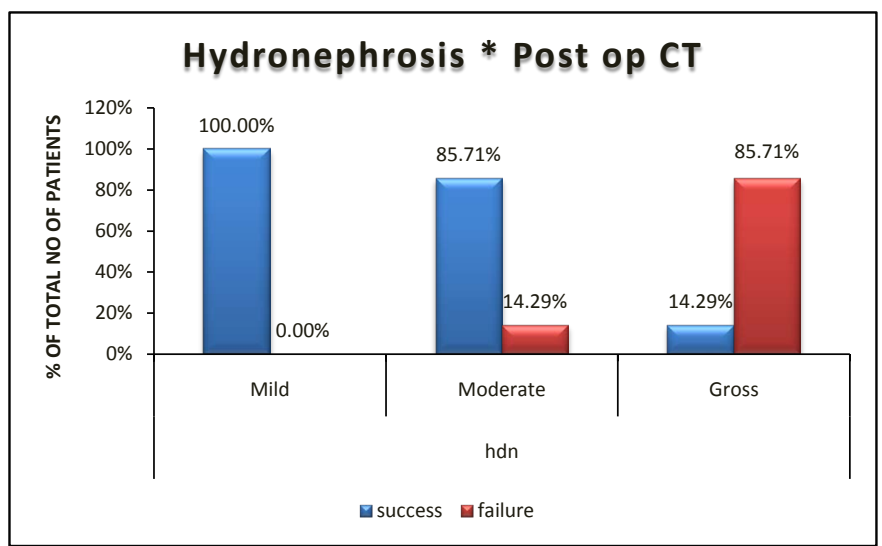

Figure 7. Hydronephrosis and outcome of URSL.

There is still controversy whether the secondary signs can predict outcome in patients with ureteral stones or not. In a report on the incidence rates of secondary signs and their influences on patient management, Ege et al. [11] identified hydroureter, hydronephrosis, periureteral edema, and unilateral renal enlargement as the most reliable signs for endoscopic removal of stones. Takahashi et al. [12] reported that the severity of perinephric edema correlates with the probability of stone expulsion spontaneously. He also suggested that the degree 
of edema indicated the seriousness of ureteral obstruction. Seitz et al. [13] reported that the presence of secondary signs before URSL did not correlate with the preoperative stone-free rate. In our study 7 out of 24 patients had gross HDN and among them 6 had failed outcome of URSL. Patients with gross HDN had poor outcome of URSL. This was because patients with gross HDN has longer duration of stone disease which resulted in impaction of stone and thus resulting in failure of URSL.

In our study the stone with higher $\mathrm{HU}$ had a negative outcome as compared to stones with a low HU. The result was in concordance with the study done by Magnunson et al. [14] who showed that Hounsfield unit reflects the stone's composition and hardness and correlates with the rate of successful ESWL.

Our study compares well with other world literature in terms of outcome of URSL. In our study the overall success rate was $75 \%$ and complication rate of $16.67 \%$. Knispel et al. had a success rate of $73.7 \%$ in his series of 135 patients who were treated with lithocast [15] Shrestha et al. had a success rate of $88.5 \%$ in 52 patients with lower ureteric calculi when treated with pneumatic lithotripter [16]. Oktay et al. and Leidi et al. also showed the success rate of $91 \%$ in lower ureteric calculi [17] [18]. Another study done by Salman et al. compared pneumatic lithotripsy and laser lithotripsy. Out of 50 patients taken for pneumatic lithotripsy, 41 patients had successful outcome giving a success rate of $82 \%$ [19]. In our study we were not able to include the later complications such as stricture formation, which has been documented in literature, due to difficulties in the further follow up.

\section{Conclusions}

Size of the stone and Hounsfield units of the stone are the factors which directly influence the outcome of URSL; the bigger the stone or the higher the HU of stone, the less the chances of complete removal of stone. Gross hydronephrosis is associated with poor outcome of URSL.

This study also points towards higher incidence of ureteric stones in males as compared to females with mean age of presentation between 20 - 40 years. We found that ureteroscopy is safe with minimal complications in the management of lower ureteric calculus.

\section{Ethical Clearance}

Study was approved by institutional ethics committee.

\section{Conflicts of Interest}

The authors declare no conflicts of interest regarding the publication of this paper.

\section{References}

[1] Masarani, M. and Dinneen, M. (2007) Ureteric Colic: New Trends in Diagnosis and 
Treatment. Postgraduate Medical Journal, 83, 469-472. https://doi.org/10.1136/pgmj.2006.055913

[2] Bhat, A., Singh, V., Bhat, M., Kumar, V. and Bhat, A. (2018) Spectrum of Urinary Stone Composition in Northwestern Rajasthan Using Fourier Transform Infrared Spectroscopy. Indian Journal of Urology, 34, 144-148. https://doi.org/10.4103/iju.IJU 36316

[3] Song, H.-J., Cho, S.-T. and Kim, K.-K. (2010) Investigation of the Location of the Ureteral Stone and Diameter of the Ureter in Patients with Renal Colic. Korean Journal of Urology, 51, 198-201. https://doi.org/10.4111/kju.2010.51.3.198

[4] Worster, A., Preyra, I., Weaver, B. and Haines, T. (2002) The Accuracy of Noncontrast Helical Computed Tomography versus Intravenous Pyelography in the Diagnosis of Suspected Acute Urolithiasis: A Meta-Analysis. Annals of Emergency Medicine, 40, 280-286.

[5] Ahmad, N.A., Ather, M.H. and Rees, J. (2003) Incidental Diagnosis of Disease on Un-Enhanced Helical Computed Tomography Performed for Ureteric Colic. BMC Urology, 3, 2-6.

[6] Mostafavi, M.R., Ernst, R.D. and Saltzman, B. (1998) Accurate Determination of Chemical Composition of Urinary Calculi by Spiral Computerized Tomography. Journal of Urology, 159, 673-675. https://doi.org/10.1016/S0022-5347(01)63698-X

[7] Motley, G., Dalrymple, N., Keesling, C., Fischer, J. and Harmon, W. (2001) Hounsfield Unit Density in the Determination of Urinary Stone Composition. Urology, 58, 170-173. https://doi.org/10.1016/S0090-4295(01)01115-3

[8] Etafy, M., Morsi, G.A.M., Beshir, M.S.M., et al. (2013) Management of Lower Ureteric Stones: A Prospective Study. Central European Journal of Urology, 66, 456-462. https://doi.org/10.5173/ceju.2013.04.art19

[9] Kim, S.Y., Kim, M.J., Yoon, C.S., Lee, M.S., Han, K.H. and Lee, M.J. (2013) Comparison of the Reliability of Two Hydronephrosis Grading Systems: The Society for Foetal Urology Grading System vs. the Onen Grading System. Clinical Radiology, 68, e484-e490. https://doi.org/10.1016/j.crad.2013.03.023

[10] Abdelrahim, A.F., Abdelmaguid, A., Abuzeid, H., Amin, M., El Mousa, S. and Abdelrahim, F. (2008) Rigid Ureteroscopy for Ureteral Stones: Factors Associated with Intraoperative Adverse Events. Journal of Endourology, 22, 277-280. https://doi.org/10.1089/end.2007.0072

[11] Ege, G., Akman, H., Kuzucu, K. and Yildiz, S. (2003) Acute Ureterolithiasis: Incidence of Secondary Signs on Unenhanced Helical CT and Influence on Patient Management. Clinical Radiology, 58, 990-994. https://doi.org/10.1016/S0009-9260(03)00294-0

[12] Takahashi, N., Kawashima, A., Ernst, R.D., Boridy, I.C., Goldman, S.M., Benson, G.S. and Sandler, C.M. (1998) Ureterolithiasis: Can Clinical Outcome Be Predicted with Unenhanced Helical CT? Radiology, 208, 97-102.

https://doi.org/10.1148/radiology.208.1.9646798

[13] Seitz, C., Memarsadeghi, M., Fajkovic, H. and Tanovic, E. (2008) Secondary Signs of Non-Enhanced CT Prior to Laser Ureterolithotripsy: Is Treatment Outcome Predictable? Journal of Endourology, 22, 415-418. https://doi.org/10.1089/end.2007.0248

[14] Magnuson, W.J., Tomera, K.M. and Lance, R.S. (2005) Hounsfield Unit Density Accurately Predicts ESWL Success. Alaska Medicine, 47, 6-9.

[15] Knispel, H., Klan, R., Heicappell, R. and Miller, K. (1998) Pneumatic Lithotripsy Applied through Deflected Working Channel of Miniureteroscope: Results in 143 
Patients. Journal of Endourology, 12, 513-515.

https://doi.org/10.1089/end.1998.12.513

[16] Shrestha, B., Karki, D. and Baidya, J. (1970) The Outcome of Pneumatic Lithotripsy for the Management of Ureteric Calculi. Kathmandu University Medical Journal, 6 355-360. https://doi.org/10.3126/kumj.v6i3.1711

[17] Leidi, G.L., Berti, G.L., Canclini, L., et al. (1997) Ureteroscopy and Stone Lithotripsy with Lithoclast: Personal Experience. Archivio Italiano di Urologia e Andrologia, 69, 181-183.

[18] Oktay, B., Yavascaoglu, I., Simsek, U. and Ozyurt, M. (1997) Intracorporeal Pneumatic Lithotripsy for Ureteral and Vesical Calculi. Scandinavian Journal of Urology and Nephrology, 31, 333-336. https://doi.org/10.3109/00365599709030615

[19] Tipu, S., Hammad, A.M., Nazim, M. and Gauhar, S. (2007) Treatment of Ureteric Calculi-Use of Holmium: YAG Laser Lithotripsy versus Pneumatic Lithoclast. The Journal of the Pakistan Medical Association, 57, 440-443. 